\title{
Clinico-histopathological and ultrasonographic correlation of abnormal uterine bleeding in perimenopausal and postmenopausal women
}

\author{
Sharanya*, Julie Thomas
}

Department of Obstetrics and Gynecology, St. Philomena Hospital, Bangalore, Karnataka, India

Received: 11 April 2021

Revised: 05 May 2021

Accepted: 06 May 2021

\section{*Correspondence:}

Dr. Sharanya,

E-mail: shrny.7@gmail.com

Copyright: $(\subset$ the author(s), publisher and licensee Medip Academy. This is an open-access article distributed under the terms of the Creative Commons Attribution Non-Commercial License, which permits unrestricted non-commercial use, distribution, and reproduction in any medium, provided the original work is properly cited.

\section{ABSTRACT}

Background: Abnormal uterine bleeding (AUB) accounts for one of the most common gynaecological problem, almost one third of total cases. The study was a prospective study done from December 2017 to November 2019. The histopathological reports of endometrial pattern as well as that of hysterectomy specimens were correlated with clinical diagnosis and ultrasonographic findings. The main objective was to study the correlation between clinical, ultrasonographic and histopathological correlation of AUB in perimenopausal, menopausal and postmenopausal women.

Methods: Formal Permission was obtained from the administrator of St. Philomena's hospital. Ethical clearance was obtained from institutional ethical review board of St. Philomena's hospital. Informed consent was obtained from observational group and confidentiality was assured. Data entry and analyses was done using the Statistical Package for Social Sciences (SPSS) for Windows software (version 20.0; SPSS Inc, Chicago).

Results: A total number of 165 cases were studied. Maximum women were in the age group of $40-55$ years $87.27 \%$. Most common presentation of abnormal uterine bleeding is menorrhagia which accounts for $72.7 \%$ of women (120 women). The most common finding noted in USG was fibroid uterus which accounts for $44.2 \%$ of women (73 women). Most commonly observed histological pattern noted were proliferative (62.4\%) followed by secretory endometrium $(8.5 \%)$ and simple endometrial hyperplasia with atypia $(8.5 \%)$.

Conclusions: In conclusion, AUB is one of the most common condition for which patients seek advice in the gynaecological outpatient department. Analysis of histopathology of endometrium in abnormal uterine bleeding helps in management of patients and to know the pathological incidence of structural causes in AUB prior to surgery.

Keywords: Abnormal uterine bleeding, Proliferative endometrium, Secretory endometrium, Endometrial hyperplasia,

\section{INTRODUCTION}

Abnormal uterine bleeding is found to be one of the commonest presenting symptom and major gynaecological problem responsible for as many as onethird of all outpatients gynaecologic visit. ${ }^{1,2}$ Woman can present with several symptoms of menstrual disturbances such as heavy menstrual bleeding, intermenstrual bleeding. Menorrhagia affects $10-30 \%$ of menstruating women at any one time and may occur at some time during the perimenopause in up to $50 \%$ of women. ${ }^{3}$

Abnormal uterine bleeding is defined as any bleeding pattern that differs in the frequency, duration and amount from a pattern observed during a normal menstrual cycle or menopause. It is a common problem having a long list of causes in different age groups. ${ }^{4}$ 
The endometrial sampling is chosen to evaluate abnormal uterine bleeding because it has several advantages over other diagnostic methods. The hormonal assay is very expensive and laboratories with hormonal assay are not available in rural areas. Ultrasonography clearly depicts the uterine contour and the status of the ovary, but fails to provide adequate information regarding the endometrium, except in atrophy and hyperplasia. Other investigations like hysteroscopy and hysterosalpingography are mainly helpful in diagnosing organic pathology. 5 The only disadvantage of endometrial biopsy is that it is an invasive procedure. ${ }^{6}$

Initially AUB was broadly divided into two categoriesanovulatory and ovulatory, but now after November 2010 the International federation of gynaecology and obstetrics finally accepted a new classification system for causes of AUB in reproductive years. The system is based on acronym PALM-COEIN, PALM (structural causes)polyps, adenomyosis, leiomyoma, malignancy and hyperplasia, COEIN (coagulopathy, ovulatory disorders, endometrial causes, iatrogenic, not classified). ${ }^{7}$ Among all the etiologies listed above, ovulatory disorders is the most common cause.

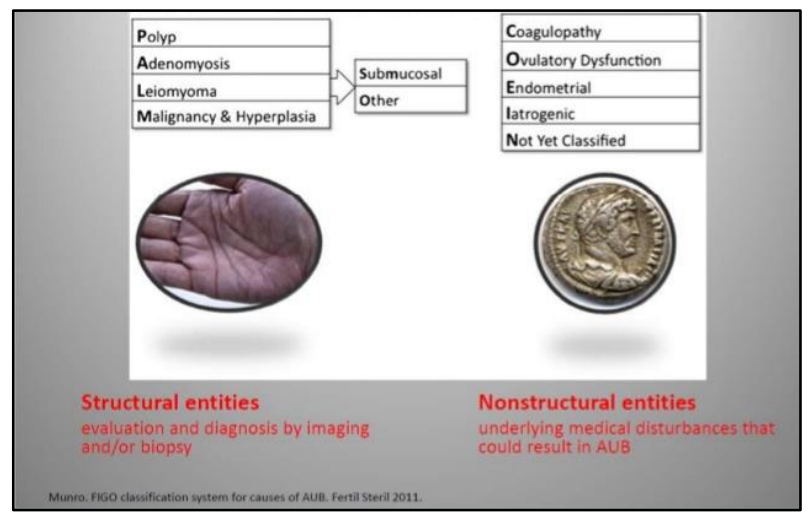

Figure 1: PALM-COEIN-FIGO classification of AUB.

\section{METHODS}

\section{Study setting}

The study was conducted in St. Philomena's Hospital in Bangalore, Karnataka.

\section{Study duration}

The duration of the study was for 24 months from December 2017 to November 2019.

\section{Study population}

165 women, perimenopausal and postmenopausal women with complaints of AUB during study period were the study population.

\section{Study design}

It was a descriptive, hospital based cross sectional study.

\section{Sampling strategy}

The sampling strategy was a non-probability (convenience sampling) study.

\section{Inclusion criteria}

Total 165 women with perimenopausal and postmenopausal presenting with abnormal uterine bleeding at St. Philomena's hospital during the study period and patients with comorbidities (DM, HTN) presenting with AUB were included in the study.

\section{Exclusion criteria}

Patient of reproductive age group presenting with AUB, patient with excessive bleeding in amount $(>80 \mathrm{ml})$, longer duration ( $>7$ days) and patients not giving consent were excluded from the study.

\section{Method of data collection}

Formal permission was obtained from the administrator of St. Philomena's hospital. Ethical clearance was obtained from institutional ethical review board of St. Philomena's hospital. Informed consent was obtained from observational group and confidentiality was assured.

\section{Statistical methods}

Appropriate statistical methods proposed for the study were applied. This is a descriptive hospital based cross sectional study involving all the women of age group 40 and above presenting with AUB after excluding the persons in exclusion criteria.

Data entry and analyses was done using the statistical package for social sciences (SPSS) for windows software (version 20.0; SPSS Inc, Chicago). Descriptive statistics such as mean and standard deviation (SD) for continuous variables and frequency and percentage for categorical variables was determined. Normality of data was first checked by using Kolmogorov Smirnov (KS) test. Chi square test and Fischer's test were used to show association between predictor and outcome variables for categorical variables and unpaired test for continuous variables having 2 groups, respectively. Mann Whitney Test was used to compare between 2 groups if data does not follow normal distribution. Pearson's correlation coefficient was calculated for showing correlation between 2 quantitative variables. Multiple logistic regression was used to know independence of each factor after nullifying the effect of other factors. The level of significance was set at 0.05 . 


\section{RESULTS}

Table 1 shows the total distribution of study subjects according to the age group. Maximum women were in the age group of 40-55 years, total 144 women $(87.27 \%)$. The range of the total study population is $40-69$ years. Mean age of the study population is 47.38 years with standard deviation of 6.26 .

Figure 1 depicts the distribution of the clinical features of the total study population. Most common presentation of abnormal uterine bleeding is menorrhagia which accounts for $72.7 \%$ of women (120 women). The next common presentation of women noted in the study was heavy menstrual bleeding which included $17.6 \%$ of women (29 women). Rarer symptoms included dysmenorrhoea $(1.2 \%)$ and oligomenorrhoea $(0.6 \%) .1$ out of the total study population, $0.6 \%$ of women was diagnosed of AUB in routine check-up.

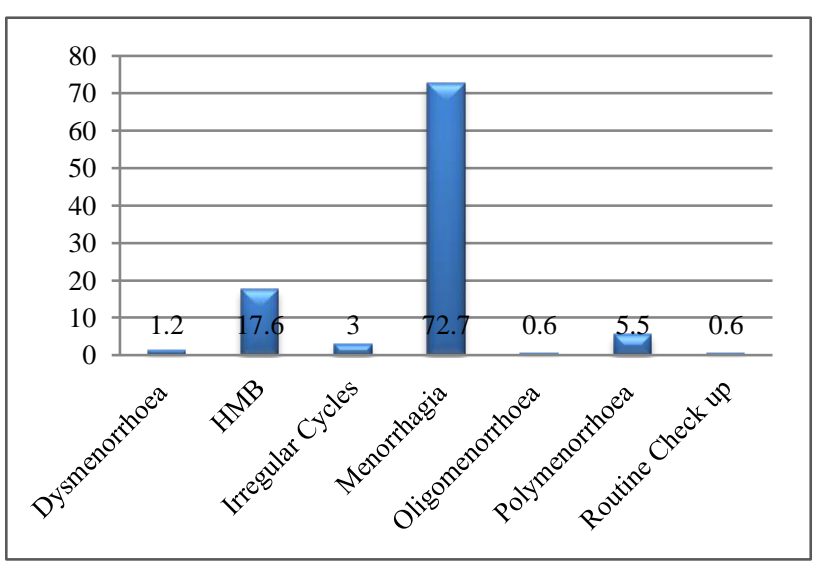

Figure 1: Distribution of clinical features.

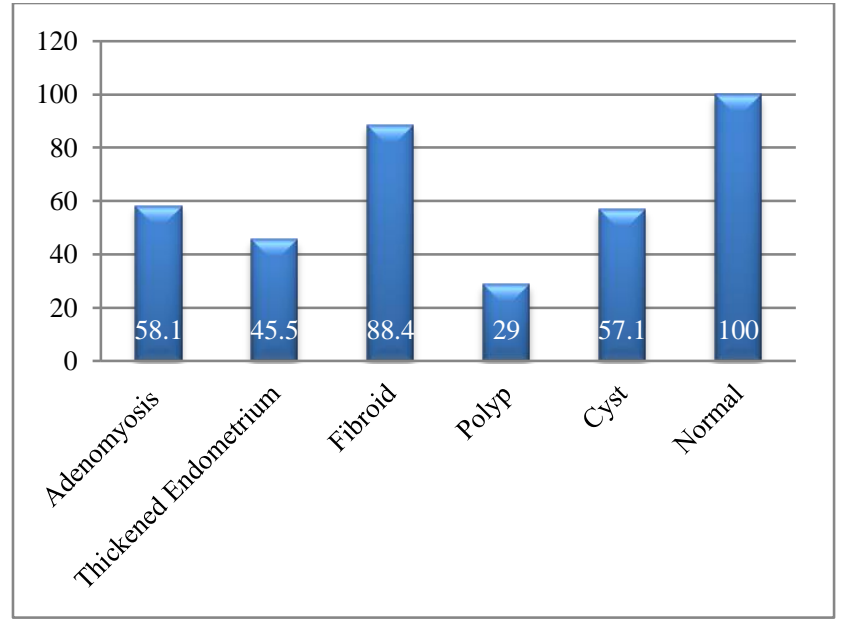

Figure 2: Sensitivity of USG with respect to HPE.

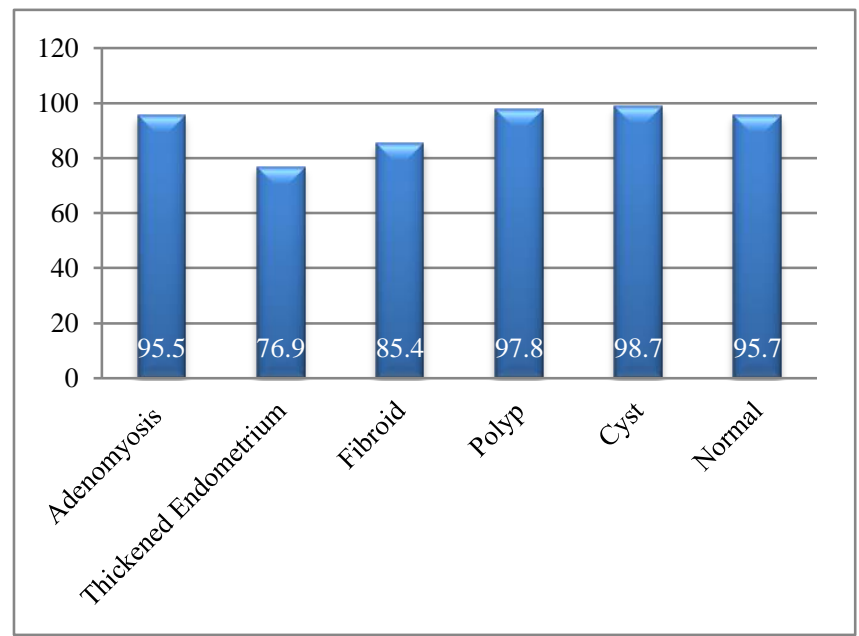

Figure 3: Specificity of USG with respect to HPE.

Table 1: Distribution of study subjects according to their age group* $(\mathrm{N}=165)$.

\begin{tabular}{|lll|}
\hline Age (in years) & Numbers & Percent $(\%)$ \\
\hline $\mathbf{4 0 - 5 5}$ & 144 & 87.27 \\
\hline$>\mathbf{5 5}$ & 21 & 12.73 \\
\hline Mean (SD) & $47.38(6.26)$ & \\
\hline Range & $40-69$ & \\
\hline
\end{tabular}

*Multiple options.

Table 2: Distribution of study subjects according to the USG findings* $(\mathrm{N}=165)$.

\begin{tabular}{|lll|}
\hline USG findings* & Numbers & Percent (\%) \\
\hline Fibroid & 73 & 44.2 \\
\hline Thickened endometrium & 47 & 28.5 \\
\hline Adenomyosis & 25 & 15.2 \\
\hline Normal & 8 & 4.8 \\
\hline Endometrial polyp & 6 & 3.6 \\
\hline Polyp & 6 & 3.6 \\
\hline Adnexal cyst & 2 & 1.2 \\
\hline Ovarian cyst & 2 & 1.2 \\
\hline
\end{tabular}




\begin{tabular}{|lll|}
\hline USG findings* & Numbers & Percent (\%) \\
\hline Cervical polyp & 1 & 0.6 \\
\hline Endometrial cyst & 1 & 0.6 \\
\hline Multiple fibroid & 1 & 0.6 \\
\hline Ovarian cystadenoma & 1 & 0.6 \\
\hline Ovarian mass & 1 & 0.6 \\
\hline Pyometra & 1 & 0.6 \\
\hline
\end{tabular}

*Multiple options.

Table 3: Distribution of study subjects according to the AUB* $(\mathbf{N}=165)$.

\begin{tabular}{|lll|}
\hline AUB & Numbers & Percent $(\%)$ \\
\hline AUB-A & 19 & 11.5 \\
\hline AUB-A/E & 1 & 0.6 \\
\hline AUB-A/L & 2 & 1.2 \\
\hline AUB-E & 40 & 24.2 \\
\hline AUB-E/L & 4 & 2.4 \\
\hline AUB-L & 66 & 40.0 \\
\hline AUB-L/A & 4 & 2.4 \\
\hline AUB-L/E & 2 & 1.2 \\
\hline AUB-N & 8 & 4.8 \\
\hline AUB-O & 6 & 3.6 \\
\hline AUB-P & 11 & 6.7 \\
\hline AUB-P/L & 2 & 1.2 \\
\hline
\end{tabular}

Table 4: Distribution of study subjects according to the Pipelle* $(\mathrm{N}=165)$.

\begin{tabular}{|lll|}
\hline Pipelle distribution & Numbers & Percent (\%) \\
\hline Atrophic endometrium & 1 & 0.6 \\
\hline Atypical polypoid adenomyoma & 3 & 1.8 \\
\hline Benign endometrial polyp & 4 & 2.4 \\
\hline Complex endometrial hyperplasia with atypia & 12 & 7.3 \\
\hline Complex endometrial hyperplasia without atypia & 1 & 0.6 \\
\hline Disintegrating endometrium & 1 & 0.6 \\
\hline Endometrial polyp & 1 & 0.6 \\
\hline Lytic endometrium & 1 & 0.6 \\
\hline Progesterone induced effect & 1 & 0.6 \\
\hline Proliferative & 103 & 62.4 \\
\hline PSTT & 1 & 0.6 \\
\hline Secretory & 14 & 8.5 \\
\hline Simple endometrial hyperplasia with atypia & 14 & 8.5 \\
\hline Simple endometrial hyperplasia with cystic change & 1 & 0.6 \\
\hline Simple endometrial hyperplasia without atypia & 5 & 3.0 \\
\hline Small clusters of stromal cells & 2 & 1.2 \\
\hline
\end{tabular}

Table 5: Comparative study of types of bleeding and AUB.

\begin{tabular}{|lll|}
\hline Type of bleeding & Mehrotra VG $(\%)$ & Present study (\%) \\
\hline Heavy menstrual bleeding (menorrhagia) & $78(52)$ & $120(72.5)$ \\
\hline Inter menstrual bleeding (metrorrhagia) & $29(19.33)$ & 0 \\
\hline Heavy and prolonged bleeding (menometrorrhagia) & 0 & $29(17.6)$ \\
\hline Frequent menstrual bleeding (polymenorrhea) & $39(26)$ & $9(5.5)$ \\
\hline Oligomenorrhea & 0 & $1(0.6)$ \\
\hline Post-menopausal bleeding & $4(2.67)$ & - \\
\hline Total & 150 & 165 \\
\hline
\end{tabular}


Table 6: Comparative analysis of histopathological findings.

\begin{tabular}{|lll|}
\hline Histological findings & Sadia Khan $(\%)$ & Present study (\%) \\
\hline Proliferative phase & $233(46.6)$ & $103(62.4)$ \\
\hline Secretory phase & $192(38.4)$ & $14(8.5)$ \\
\hline Simple hyperplasia without atypia & $32(6.4)$ & $1(0.6)$ \\
\hline Simple hyperplasia with atypia & $12(2.4)$ & $14(8.5)$ \\
\hline Complex hyperplasia without atypia & $14(2.8)$ & $1(0.6)$ \\
\hline Complex hyperplasia with atypia & 0 & $12(7.3)$ \\
\hline Endometrial polyp & $3(0.6)$ & $1(0.6)$ \\
\hline Disordered proliferative endometrium & 0 & $2(1.2)$ \\
\hline Mixed endometrium & 0 & $3(1.8)$ \\
\hline Endometritis & $2(0.4)$ & 0 \\
\hline Atrophic endometrium & $5(1)$ & $1(0.6)$ \\
\hline Endometrial adenocarcinoma & $2(0.4)$ & 0 \\
\hline Total & 500 & 165 \\
\hline
\end{tabular}

Table 2 depicts the distribution of study population according to ultrasonographic (USG) findings. The most common finding noted was fibroid uterus which accounts for $44.2 \%$ of women (73 women). The second common finding in the study was thickened endometrium which comprises $28.5 \%$ of women (47 women). The rarer USG findings noted were cervical polyp, endometrial cyst, multiple fibroid, ovarian cystadenoma, ovarian mass, pyometra all accounting for $0.6 \%$ of cases each.

Table 3 depicts the no. of study subjects in the different categories of PALM-COEIN classification. The maximum subjects were seen in AUB-L followed by AUB-E followed by AUB-A. The least common type seen was AUB-A/E.

Table 4 depicts the distribution of study subjects in various pipelle categories. Most observed were proliferative $(62.4 \%)$ followed by secretory endometrium $(8.5 \%)$ and simple endometrial hyperplasia with atypia $(8.5 \%)$.

Figure 2 depicts the sensitivity of USG with respect to HPE. Most sensitive parameter was normal ultrasound (100\%) followed by fibroid which accounts for $88.4 \%$ of cases.

Figure 3 depicts specificity of USG with respect to HPE with maximum specificity of cyst followed by polyp followed by normal finding.

\section{DISCUSSION}

AUB continues to be one of the most common and perplexing problems in gynaecological practice. It may present at any age between puberty and menopause. It may be associated with various kinds of histopathological findings in the endometrium.
In the study done by Sadia Khan, proliferative phase was most common histological pattern followed by secretory phase, simple hyperplasia without atypia, complex hyperplasia without atypia, atrophic endometrium, endometrial polyp, endometritis and endometrial adenocarcinoma in that order. In the present study also the most common pattern observed was proliferative followed by secretory phase and simple endometrial hyperplasia with atypia. Least common pattern noted were endometritis and endometrial adenocarcinoma. ${ }^{8}$

\section{Limitations}

Medical versus surgical management advantages and disadvantages could not made out. Follow-up of all the patients could not be done. The study was conducted at a single centre. Multicentric study will give a better picture of the correlation. Long term consequences of different conditions of AUB could not be made out. Sample size of this study were relatively smaller sample size

\section{CONCLUSION}

The present study highlights the importance of endometrial biopsy and its interpretation which plays a pivotal role in the management of AUB.

Histopathological examination of endometrial biopsies in patients of AUB shows a wide spectrum of changes ranging from normal endometrium in various hormonal cycles to malignancy.

In present study, the most frequent finding seen in patients with AUB in their productive age group was proliferative phase. In peri and postmenopausal women simple hyperplasia without atypia was most frequently noted.

Accurate diagnosis of the causative factor of abnormal uterine bleeding in any age group is of importance so that 
appropriate management can be initiated. Therefore, histological characteristics of endometrial samples as assessed by light microscopy remains the gold standard for clinical diagnosis of endometrial pathology.

Funding: No funding sources

Conflict of interest: None declared

Ethical approval: The study was approved by the Institutional Ethics Committee

\section{REFERENCES}

1. William BJ. The Abnormal Menstrual Cycle, Textbook of Endometrium. Massachusetts: Butterworth; 1981: 45-72.

2. Kjeerulff KH, Erickson BA, Langenberg PW. Chronic gynaecological conditions reported by US women: finding from the national health interview survey, 1984 to 1992. Am J Public Health. 1996;86(2):195-9.

3. Rees M, Hope S. The abnormal menstrual cycle. Market Opinion and Research International (MORI). London. 1990;342:1375.
4. Barnard K, Frayne SM, Skinner KM, Sullivan LM. Health status among women with menstrual symptoms. J Women's Health (Larchmt). 2003;12(9):911-9.

5. Cote I, Jacobs P, Cumming D. Work loss associated with increased menstrual loss in United States. Obstet Gynecol. 2002;100(4):683-7.

6. Fluhmann CF. Textbook of Menstrual Disorders and treatment. Philadelphia: W. B. Saunders Company; 1956: $1-4$.

7. Munro MG, Critchley HOD, Fraser IS. The FIGO systems for nomenclature and classification of causes of Abnormal Uterine Bleeding in reproductive years who needs them? AJOG. 2018;143(7):393-408.

8. Baral R, Pudasaini S. Histopathological pattern of endometrial samples in abnormal uterine bleeding. $\mathrm{J}$ Path Nepal .2011;1(1):13-6.

Cite this article as: Sharanya, Thomas J. Clinicohistopathological and ultrasonographic correlation of abnormal uterine bleeding in perimenopausal and postmenopausal women. Int J Reprod Contracept Obstet Gynecol 2021;10:2408-13. 